\title{
Comparison Study of Prospecting Concealed Uranium Deposit By Geoelectrochemical Methods in China and Australia
}

\author{
XIANRONG LUO ${ }^{1}$, WEN GAO $^{1,2}$, FEI OUYANG ${ }^{1,3}$, \\ PANFENG LIU ${ }^{1,4}$ \\ ${ }^{1}$ Guilin University of Technology, Guilin 541004, China \\ 972475619@qq.com \\ ${ }^{2}$ Guilin University of Technology, Guilin 541004, China \\ gwgwly@sina.com \\ ${ }^{3}$ Guilin University of Technology, Guilin 541004, China \\ 54836902@qq.com \\ ${ }^{4}$ Guilin University of Technology, Guilin 541004, China \\ 1056763179@qq.com
}

Exploration of uranium mine has always been an important part of the national strategic resource reserve process. At the same time, due to the lack of direct prospecting indicators in the process of searching for concealed deposits, the available mineralization information is less, and the reliability of the prospecting method needs to be improved. Therefore, geoelectrochemical methods are applied in the exploration of concealed uranium deposits. Geoelectrochemical methods include geoelectrochemical extraction, soil ion conductivity, and soil thermorelease mercury. Based on the results of three methods, the purpose of searching for concealed uranium deposits is achieved. The study work was conducted in the Huxi mining area in Le'an County, Jiangxi Province, China, and the Four Mile East mining area in Australia. Through comparison, the uranium mine belongs to the volcanic rock type in the Huxi mining area, it was found that the correlation of $\mathrm{U}, \mathrm{Th}, \mathrm{Mo}$, and $\mathrm{Pb}$ is good, which can be used as better indicator elements for ore prospecting. The change range of elements above the known ore body is $\mathrm{Th}>\mathrm{U}>$ Mo. Although the anomalies of soil ion conductivity has a certain indicator effect on the ore body, it can not be used for ore prospecting alone. The anomalies of soil thermorelease mercury has an effect on ore prospecting. The uranium mine belongs to the type of sedimentary sandstone type in the Four Mile East. the correlation of U, $\mathrm{Mo}, \mathrm{Ag}$ and $\mathrm{V}$ is good, which can be used as a better indicator element for prospecting. The change range of elements above the known ore body is $\mathrm{U}>\mathrm{Mo}$, and the soil ion conductivity anomaly has a good indication of the location of the ore body, and the anomalies of thermorelease mercury has little significance for determining the location of the ore body. The results show that the comprehensive analysis of anomalies combined with geological characteristics can achieve good prospecting results. 